\title{
IMPROVED TRICEPS SUBSTITUTE BRACE
}

\author{
By Roy H. Nyquist, M.D. and LoRen C. Blaylock, Certified Orthotist \\ From the Spinal Cord Injury and Prosthetic Services of the Veterans \\ Administration Hospital, Long Beach, California
}

THIS article describes an improved upper extremity brace with triceps substitution action. This new brace is lighter and stronger than the previous model (Shear \& Comarr, 1950). The new type of spring used at the elbow joint is more easily procured, can be adjusted to various tensions, and can even be reversed to assist weak, or to replace lacking, biceps action. It is called the Hosmer Flail-arm Hinge. The forearm portion of this new brace has a new feature which permits supination and pronation of the forearm over a range of $180^{\circ}$. This consists of a rod with a 'V'-shaped groove, held within a tube by a screw with a 'V'-shaped pointed end, allowing the rod to rotate within the tube. The newly designed arm and forearm cuffs with Velcro fasteners as well as buckles and straps improve the fit of the brace to the upper extremity and thereby its function.

This brace is useful in patients with traumatic tetraplegia below C- 5 or 6 who have good biceps but no triceps strength. The triceps action supplied by the string at the elbow joint of the brace stabilises the action of the biceps muscle at the elbow. It is furthermore useful in quadriplegic patients with early contractures at the elbow because is exerts a gentle stretch.

Use of the substitute triceps action brace permits limited extension of the elbow against gravity, facilitating the use of the shoulder wheel; it also assists the patient in controlling movement in such activities as putting the hand on the head or moving a steering wheel.

Quadriplegic exercise gloves can be used in conjunction with this brace. If desired, attachments for eating, writing, toiletry, etc. can be added to the hand portion.

Illustrations I-4 show details of construction and use of the brace.

\section{SUMMARY}

The new improved triceps substitute brace is light, strong, fits the upper extremity better, and permits pronation and supination of the forearm. It weighs I6 oz. ( $480 \mathrm{~g}$.) as compared with the weight of our previous brace of $28 \mathrm{oz}$. (840 g.). The elbow spring is adjustable allowing increase or decrease in the tension of the triceps replacement action. The illustrations I-4 describe the details of construction. The indications for the use of the brace are mentioned.

\section{RÉSUMÉ}

L'appareillage permettant de substituer l'action du triceps est léger, solide, s'adapte mieux aux membres supérieurs, et permet la prono-supination de l'avant-bras. Il pèse I6 onces ( $480 \mathrm{gr}$ ), comparé au poids d'un appareillage similaire de 28 onces ( $840 \mathrm{gr}$ ). Le ressort du coude peut-être ajusté, permettant l'augmentation ou la diminution de la tension de remplacement tricipital. Les illustrations de I à 4 décrivent en détail la construction de l'appareil. Les indications pour l'utilisation de cette orthèse sont données. 


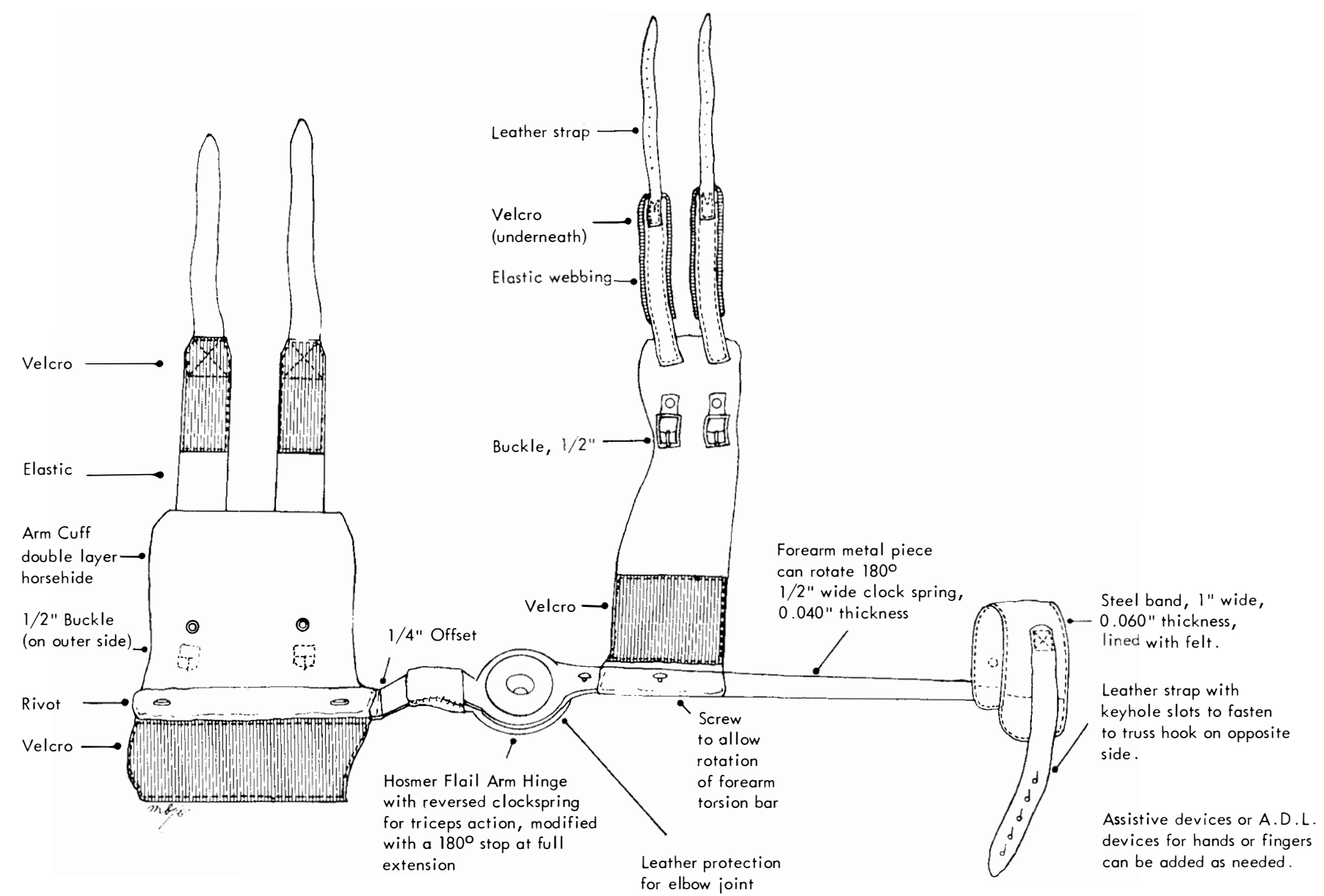

FIG. I

This diagram shows the construction of the cuffs for arm and forearm. Proper fitting and fastening of the brace over the biceps muscle is important and this is secured by means of the Velcro fasteners in addition to the straps and buckles as shown. The construction at the elbow and forearm portions of the brace are also described. 


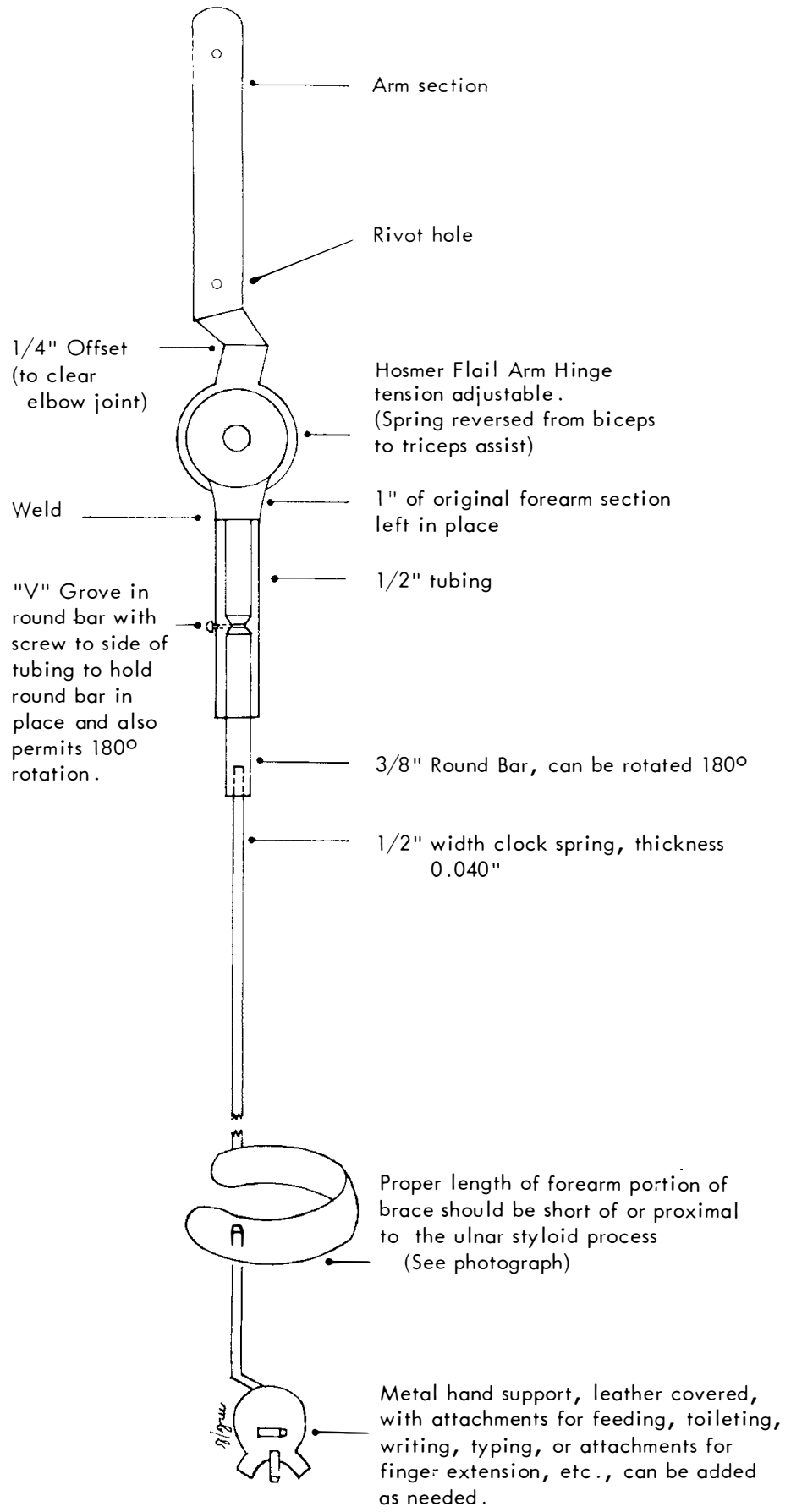

FIG. 2

This is a diagram of the metal construction which reduced the weight of the brace from $28 \mathrm{oz}$. ( $840 \mathrm{~g}$.) to I6 oz. ( $480 \mathrm{~g}$.). It also shows how pronation and supination of the forearm portion is possible by means of a rod with a ' $\mathrm{V}$ '-shaped groove. This is held in place by a pointed setscrew which is not fastened tight enough to prevent rotation but only to prevent withdrawal. 


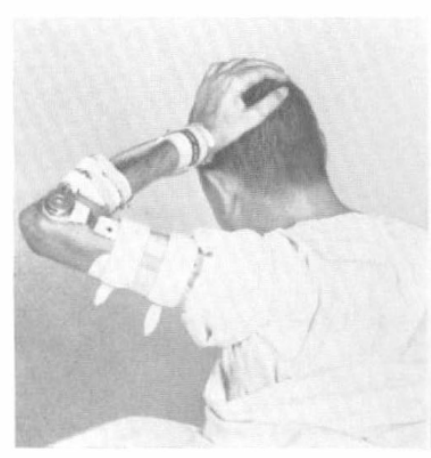

FIG. 3

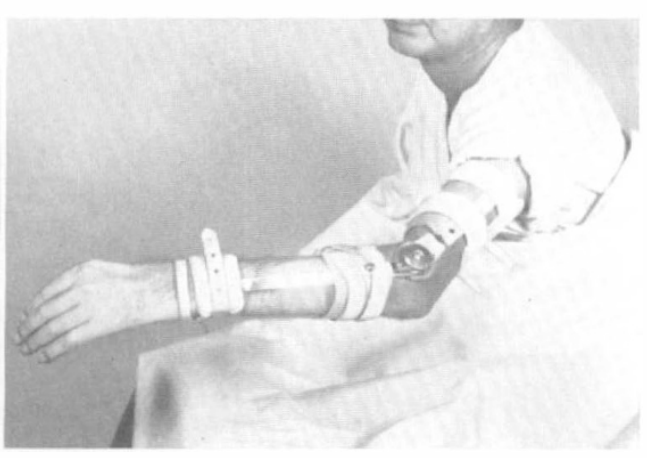

FIG. 4

Fig. 3.-This shows the brace with flexion of the elbow and demonstrates supination of the forearm portion.

Fig. 4.-This shows the brace with extension of the elbow and demonstrates pronation of the forearm portion.

\section{ZUSAMMENFASSUNG}

Der neue verbesserte Stützapparat für den Ersatz des Triceps ist leicht und stark, er passt sich besser der oberen Extremität an und erlaubt Pronation und Supination des Unterarms. Er wiegt 16 oz. (840 Gramm). Die Sprungfeder für den Ellbogen ist verstellbar und ermöglicht Zunahme und Abnahme in der Spannung der Ersatzfunktion des Triceps. Die Illustrationen I-4 beschreiben Einzelheiten der Konstruktion. Die Indikationen für die Anwendung des Stützapparates werden erwähnt.

We extend thanks to the Medical Illustration Department for the photographs and drawings.

\section{REFERENCE}

Shear, H. R. \& Comarr, A. E. (1950). Archives of Physical Medicine, 31, 518-520. 